University of Washington Tacoma

UW Tacoma Digital Commons

Urban Studies Publications

Urban Studies

3-17-2015

\title{
The Impact of Advocacy Organizations on Low- Income Housing Policy in U.S. Cities
}

Anaid Yerena

University of Washington - Tacoma, yerena@uw.edu

Follow this and additional works at: https://digitalcommons.tacoma.uw.edu/urban_pub

Part of the Urban Studies Commons

\section{Recommended Citation}

Yerena, Anaid, "The Impact of Advocacy Organizations on Low-Income Housing Policy in U.S. Cities" (2015). Urban Studies Publications. 47.

https://digitalcommons.tacoma.uw.edu/urban_pub/47

This Article is brought to you for free and open access by the Urban Studies at UW Tacoma Digital Commons. It has been accepted for inclusion in Urban Studies Publications by an authorized administrator of UW Tacoma Digital Commons. 
Yerena, A. 2015 "The Impact of Advocacy Organizations on Low-Income Housing Policy in U.S. Cities." Urban Affairs Review 51(6)

\title{
THE IMPACT OF ADVOCACY ORganizaTIONS ON Low-InCome Housing Policy IN U.S. Cities
}

By Anaid Yerena, Ph.D.

\begin{abstract}
Financial support for affordable housing competes with many other municipal priorities. This work seeks to explain the variation in support for affordable housing among U.S. cities with populations of 100,000 or more. Using multivariate statistical analysis, this research investigates political explanations for the level of city expenditures on housing and community expenditures with a particular interest in the influence of housing advocacy organizations (AOs). Data for the model were gathered from secondary sources including the U.S. Census and the National Center for Charitable Statistics. Among other results, the analysis indicates that, on average, the political maturity of AOs has a statistically significant, positive effect on local housing and community development expenditures.
\end{abstract}

KEY WORDS: affordable housing, advocacy organizations, municipal expenditures

Affordable housing ${ }^{1}$ continues to be a critical problem in the United States. The gap between the housing units needed and those available to lower-income Americans increases every year (Schwartz 2010). Furthermore, recent economic and foreclosure crises have exacerbated housing problems, leading to an escalation in first-time homelessness cases, an increase in overcrowding due to "doubling up", a rise in negative equity on mortgaged properties, and a decrease in the homeownership rate (Bostic and Ellen 2014; HUD 2009; 2013; Wassmer 2011; Iversen, Napolitano and Furstenberg 2011; Gerardi, Ross and Willen 2011).

Advocacy organizations (AOs) that address affordable housing needs mobilize public support for a variety of purposes including, but not limited to: 1) providing individuals or groups access to services, 2) protecting and expanding their constituents' rights, 3) calling for policy change, and 4) educating the broader public on their subject issue (Duncan 2004). This 
mobilization is particularly important now, in the context of ever-increasing state retrenchment (Newman and Ashton 2013), because interest group competition for scarce resources intensifies during times of fiscal stress and public budget cuts tend to target programs that redistribute resources and serve beneficiaries with little influence on decision-making (Levine, Rubin and Wolohojian 1981; Jimenez 2009; Craig and Inman 1986). The provision of affordable housing is one important example of the redistributive role of government with a diffuse constituency; thus, it is a focus of many AOs at all levels of government (Peterson 1981; Bratt 2012).

Housing scholars need to better assess and evaluate the (often less obvious) activities AOs undertake in social mobilization. Kreisi (1995) suggests social mobilization in the form of social movements can "turn into indirect forms of political representation, like parties or interest groups, or take on constituency/client-oriented activities that produce nonpolitical organizations, for either service or self-help purposes" (in Jenkins 1995, p. 19). This type of activism is critical to our understanding of the political action of the poor and disenfranchised (Fraser 2005) across policy domains, including low-income housing. Previous studies that predict local expenditures on affordable housing, such as Basolo (1999a) and Goetz (1995), have relied on survey data of local officials to account for local advocacy efforts. This study, alternatively, proposes more readily available and objective measures of advocacy organizations. These new measures can more accurately specify the effect these groups have on this political process.

This research focuses on advocacy organizations working to support affordable housing through a broad range of activities including service provision related to affordable housing need. While this advocacy work is carried out at the national, state and local levels, it is in the local arena where AOs are particularly vital to the planning and production of affordable housing in communities. It is in communities that decisions are made concerning local land use and 
budgetary priorities. AOs in these contexts exert pressure on city policymakers and participate in the decision-making process in an effort to increase affordable housing opportunities in their communities.

The research draws on theories of urban politics to test hypotheses about the housing policymaking process in U.S. cities (see Davies and Imbroscio 2009, for an overview of urban political theories). Specifically, this research builds upon existing theoretical and empirical work at the intersection of urban politics and housing policy (Basolo 1999a, 1999b; Goetz 1995; O’Connell 2012), with a focus on AOs as key participants in the process. The research asks: "Why do U.S. cities vary in their expenditures on housing and community development (HCD), specifically, what is the relative influence of local housing AOs on support for HCD expenditures?" To answer this question, the study examines U.S. cities with a population of 100,000 or more, using data from multiple secondary sources and statistical regression analysis.

The remainder of this article is organized into four sections. First, I review the theories of urban politics that undergird the study and the predictions they make about local policymaking. Second, I discuss the research design and present the methods, data, and variables used in the research. In the third section, I present descriptive data and the results from the multivariate analysis. Finally, I discuss the implications of the results as well as directions for future research.

\section{Theoretical And Empirical Perspectives}

Local government decisions are made in an increasingly resource-constrained environment in which national government transfers are being reduced, local responsibilities are increasing, and the political costs of tax increases appear to be high (Jimenez 2009). The policy outcomes produced in this context are the result of the interaction of multiple influencing actors. Theories of urban politics and policymaking are plentiful and include, among others, urban 
governance and related interest group contributions (Stoker 2000; Pierre 2014) as well as rational and structural arguments from public choice (Peterson 1981). These theories provide numerous explanations for the role of political processes in policy outcomes.

The following discussion provides a brief overview of work on urban politics drawn from both theoretically-driven and empirically-based studies. In particular, I examine several strands of the literature which are helpful in understanding the potential influence of AOs' on HCD expenditures at the local level.

\section{Urban Governance Framework}

Government, in democratic societies, is the institution that is entrusted with the power to make decisions and enforce them. Its purpose is broadly defined as maintaining public order and facilitating collective endeavors (Stoker 2000; Pierre 2014). It is this last task that has, especially in the last twenty years, promoted the participation of various relevant actors in the decisionmaking process. Governance, therefore, signifies a different process of making decisions, one in which the boundaries between public and private sectors become blurred and outputs are produced as the result of the interaction of multiple influencing actors (Innes and Booher 2004). In this study, I use the governance framework to explain the participation of AOs in the political process.

Governance recognizes that the scope and responsibility of governing extends beyond government (Innes and Booher 2004; Stoker 1998; Pierre 2014). Governance also acknowledges that the capacity to achieve goals does not rest solely on the shoulders of government; instead, it also rests on "autonomous self-governing networks of actors" (Stoker 1998, p. 18), who participate actively in the process (Slater and Aiken 2014). Finally, governance focuses on public decisions achieved through collective action "in conditions where it is not possible to rest on 
recourse to the authority of the state" (Stoker 2000, p. 93). These decisions are negotiated among the political actors that participate in the governance process and thus, also aid in the decision's implementation (Schmitter, 2002). Myriad organizations (i.e., public, private, not-for-profit) interact with policymakers and other government officials. Dynamic interactions, for example, between advocacy organizations and local government, are a part of the current political sphere. The process of interacting is inherent in this new style of governing because no single actor has the knowledge and capacity to solve the issues at hand (Rhodes 2007). Put simply, there is a need for local government to share leadership, build partnerships, protect and regulate their milieu and foster opportunities (Pierre 2014). The decision-making process, in turn, becomes more effective when it supports and builds on the interactions among public sector agencies, business organizations, advocacy groups, and foundations (Innes and Booher 2004).

Recent work (Swyngedouw, 2005) has problematized whether this new form of (urban) governance is truly empowering and democratizing the participation of groups otherwise excluded from the decision-making process. The work presents an alternate perspective on how urban governance is implemented, such as, government designating a limited area where NGOs, social movements, and insurgent planners can work (Sandercock, 1998). Thus the state becomes more autocratic and through urban governance "diffuses and consolidates the 'market' as the principal institutional form" (Swyngedouw, 2005, p. 2003). This perspective identifies these shortcomings of the urban governance framework and notes that state devolvement of responsibilities to civil society preempts its range of action. Despite these criticisms, the governance framework is a useful way to understand the roles of various actors in cities.

As the state steps back and responsibility for certain goals shifts to the citizenry, the urban governance framework has become crucial to local decision-making. Moreover, under this 
framework, it seems clear that AOs and similar organizations have better access to influence the policymaking process. In the affordable housing policy arena, AOs are the closest thing to a core constituency for affordable housing. Unlike the constituencies representing other interests (e.g., banks, real-estate agencies, insurance companies), AOs typically are not the consumers of the "product," but rather are the groups that give a voice to a population in need (Bratt and Keating 1993). This framework identifies the increased involvement of AOs and similar organizations as necessary to the provision of targeted services and strategic decision-making. Under this organizing framework, one must identify and acknowledge the contributions of voluntary and third sector organizations, such as AOs, in tackling problems related to social issues such as affordable housing. The scale and scope of their contribution within the affordable housing domain, however, has yet to be fully understood.

Urban governance may be considered a macro or structural level conceptualization, but individual agents (micro-level) take actions within these larger processes. In fact, as mentioned above, there are various agents (individuals and groups) active in the governance of a city. Advocacy organizations (AOs) are one type of agent with the potential to impact public decisionmaking.

Interestingly, there is not a universal definition of AO across academic disciplines. Political science equates an AO with an interest group, specifically a public interest or social issue interest group (Browne 1998). However, other views of these organizations emphasize the term advocacy. According to Cohen and Watson (2001), advocacy can seek impact at the level of a specific policy, governance, or civil society. Advocacy can thus achieve law and program gains that benefit its constituency, open up channels of communication so its constituency can take part in the decision-making process, and build the capacity of its constituents to influence 
decision-makers and create democratic and accountable structures. Andrews and Edwards' (2004) conceptualize an AO as a group or organization that makes public interest claims [advocates] to promote or resist the course of social change. This conceptualization includes organizations that provide resources and facilitate or are drawn into political debates, social movements, or policy advocacy.

More recently, MacIndoe and Whalen (2013) provided a concise definition of policy advocacy, as the activities organizations undertake to change or prevent change to the policies that affect the organizations and their constituents. These authors also note that while policy advocacy may not be the primary mission of some organizations, these organizations and the work they do still has "great potential to impact" (p. 120) policies².

For the purpose of this study, I adopt McIndoe and Whalen's (2013) policy advocacy definition that includes any activity a person or organization undertakes to influence policies. This is an inclusive definition, recognizing a range of AO activities, such as public demonstrations, the filing of friend of the court briefs, and lobbying ${ }^{3}$, which involve "pressure to get action by an official organization such as a city" (Basolo 1997, p. 50). For example, a local citizens' group might encourage participation from and organize local residents so they attend city council meetings in support of the construction of an affordable housing complex, or a service-providing $\mathrm{AO}$ might directly contact elected officials to request/demand a specific program continue to be funded. The organizations that fall within the purview of this study are all non-profit organizations whose missions are related to housing and shelter and are involved in activities that would include some form of policy advocacy.

Broadly speaking, AOs, whether referred to as public interest groups, non-profit organizations, or simply agents of change, can influence public decision-making processes. The 
scholarly literature reveals these organizations have been studied extensively at the federal level in the U.S. For example, Stone (1976) and Campbell (1988) found bureaucratic agencies at the federal level are subject to substantial interest group influence (see also Berry 1977). However, it is unclear if these findings are directly transferable to cities and local interest groups where many deliberative processes occur at the meso- and micro-level, and where AOs often direct their strategic actions.

Local AOs and their impact on the city policymaking process have been studied but far less frequently than work at the federal level. Existing urban research studying particular policy domains has found AOs to be influential in city politics (Prakash and Gugerty 2010; Goetz 1995; Basolo 1999a; Lucio and De la Cruz 2012). Some of these studies focused on the affordable housing policy domain and included consideration of some form of AO in their investigations. Goetz's (1995) study included a survey measure of housing activism by community-based advocates in his model of city housing expenditures. Basolo's (1999b) study identifies only a weak effect of housing non-profit organizations (also measured by survey reports from local officials) on the decision-making process when determining whether the city spends its own resources or not, but this effect is lost when modeling the effect AOs have on the amount spent. Finally, Lucio and De la Cruz (2012) identify local non-profit organizations as key actors in the affordable housing policy network in their case study of Phoenix, Arizona. While their study is valuable in understanding influence of AOs in regional housing networks, it remains unclear whether AOs exert similar influence in other urban environments.

\section{Public Choice and Inter-city competition}

For the better part of the past century, economists and political scientists have studied why cities make the decisions they make and what motivates a city to provide more support for 
one issue rather than another (Mueller 2008). More recently, political sociologists and planners have joined the conversation and contributed to our understanding of how and why policy decisions are made (Amenta 2006; Amenta et al. 2012; Basolo 1999b; Basolo and Lowery 2010; Meyer 2012). I incorporate inter-city competition into my analysis as a competing hypothesis to what influences a city's decision to spend on HCD.

Public choice theory is a classic approach to understanding decision-making and related outcomes. This body of theory is based on microeconomic principles and assumes rational behavior and a competitive market process. As applied to local decision-making, these theories postulate that cities seek to attract a population with specific socio-demographic characteristics (i.e., middle- to upper-income residents), because they provide economic benefits to the city. Thus, cities within a regional market compete with one another for more affluent residents. Cities compete with each other through the policies enacted by their elected officials, particularly spending and service provision policies (Parks and Oakerson 1989; Schneider 1989; Lyons et al. 1992; Downs 1994; Rusk 1995; Basolo 2003).

Work by Charles Tiebout (1956) is at the center of the public choice perspective. He argued that individuals, as rational actors, can choose to live in a city that maximizes their utility (understood as preferences) in terms of local services. His theoretical argument contends that if a community does not satisfy the preference of an individual, the person will "vote with [his/her] feet" by moving to another community in the region. In this way, for cities, the possibility of resident mobility acts as a check or constraint on public decision-making. At the regional level, this perspective suggests that population patterns reflect preferences for public goods much like the process of markets for private goods. 
Tiebout's theory involved highly restrictive assumptions and excludes politics (Epple and Zelenitz 1981; Bewley 1981); nevertheless, many scholars agree that the relative costs (taxes) and benefits (government services) of a community influence residential choice location decisions (Peterson 1981). Residential choice, of course, depends on more than just these two variables (Percy et al. 1995); however, Peterson (1981) notes that city officials do not have control over many factors, such as household composition or place attachment, associated with residential location decisions. Local government officials, however, can make decisions to contain local taxes and expenditures, which will tend to attract residents. Peterson contends that in making these decisions, local officials are acting in the city's economic interest, favoring developmental policies and discouraging the adoption of redistributive policies (1981). Thus, Peterson elaborates on Tiebout's theory by arguing that inter-city competition affects local decision-making differently depending on the policy domain.

The Tiebout-Peterson perspective has influenced urban research for many decades (Stein 1987; Schneider 1989; Weiher 1991; Dowding et al. 1994; Downs 1994; Longoria 1994; Percy et al. 1995; Fischel 2001; Basolo and Lowery 2010). Urban researchers have found that interjurisdictional competition within a regional market affects local public policy decisions (Aurand 2007; Basolo 2000; Basolo and Lowery 2010; Campbell 2004; Schneider 1989). For instance, Basolo's (1999b, 2000) research investigates the effect of competition and other factors on expenditures ${ }^{4}$ for economic development versus affordable housing in a sample of U.S. cities. The results show that inter-city competition increases the likelihood that a city would favor economic development spending compared to spending on affordable housing. Basolo also finds that several political variables influence policy decisions more than inter-city competition. However, in Basolo's research, the measure of advocacy organization (non-profit housing 
organizations) activity is not objectively measured, but rather was reported by city officials in response to a survey question, and had limited variation bias because it was measured on a scale from 1 to 7.

\section{Contextual Factors}

Political decision-making can be influenced substantially by "environmental" or contextual variables (Basolo 2000; Blomquist 2007; Dawson and Robinson 1963; Dye 1965; Waste 1989). Local political culture, for example, can affect policies adopted by cities. Research on urban political culture concerns the underlying beliefs or value system of a community. While some studies have found political culture is strongly related to city expenditures (Sharp 2005), and has strong effects on the decisions city officials in the U.S. made during times of financial stress (Clark and Walter 1991), others have shown only a slight effect (Goetz 1995). These mixed findings may be due to the difficulty of measuring political culture quantitatively and the use of different measures by researchers. For example, Clark and Ferguson (1983) developed a political culture typology based on cities' attitudes toward fiscal and social policies, while Sharkansky (1969) developed a political culture scale using religious, racial, and ethnic indicators.

More recently, studies of urban politics have moved away from these traditional ways of measuring political culture, and toward employing measures of what is now termed "new political culture" or "unconventional culture" (Clark 1998; Sharp 2005, 2007; Rosdil 2011). These measures reflect cultural shifts, such as women's current social roles or nontraditional household arrangements, increase of female labor participation, prevalence of postsecondary education, increase in scientific/technical and creative occupations, and household composition, that emerged in the last half century. Sharp's (2005) study provides a conceptual clarification 
and construct validity test of two new political culture measures. For the purpose of construct validation, Sharp (2005) compares the Index of Unconventional Culture and the New Political Culture Index to Elazar's (1966) classic political culture formulation and Lieske's (2010) update of Elazar. Sharp finds that each had strengths and weaknesses, and points out that a practical benefit of using the Unconventional Culture Index over the New Political Culture Index is in the availability of the data through the U.S. Census.

An example of a study explaining the policy effects of unconventional culture is Rosdil's (2011) case study of Las Vegas and Seattle, two cities with opposing political cultures and divergent development policy outcomes. Rosdil finds that Seattle, which has an unconventional culture typified by a higher than the national average percentage of both nontraditional families and college educated residents, opposed development policies (e.g., the construction of a 60-acre commercial and mixed-use project) and instead favored "progressive planning strategies"5 (p. 3481). On the other hand, the city of Las Vegas's political culture is characterized by its high proportion of married persons and a lower than the national average percentage of non-family households, was more supportive of development policies (e.g., the approval to build the $\$ 6$ billion Union Park, as a new-downtown, next to the existing downtown). Decision-makers in the city "eagerly embrace additional growth and make every effort to accommodate it with the necessary infrastructural support" (p. 3482). In another study, Horrigmo (2013) also finds that new political culture variables, such as women's participation and education level, can help explain local policy decisions, specifically regarding choices related to the level of spending on cultural policies.

In addition to political influences, extant studies have found numerous local characteristics to be influential in the policymaking process. For example, the fiscal condition of 
a city, population, residents' income, poverty level, and unemployment appear to impact city support for certain types of policies (Basolo 1999a; Basolo and Huang 2001; Goetz 1995; Waste 1989; Clark and Ferguson 1983; Wong 1990; Clark and Walter 1991).

The literature reviewed in this section indicates that AOs influence housing policy in cities, but the evidence is limited. In this article, I aim to better operationalize their influence through measures available from the National Center for Charitable Statistics. Thus, this work will add to the literature examining whether AOs, as actors in the governance of the city, influence housing and community development expenditures. In the next section, I present the research design, study methodology, data and variables.

\section{Research Design And Methodology}

The research is designed to investigate affordable housing policy decision-making by larger U.S. cities. The research asks: (1) "Why do U.S. cities vary in their expenditures on housing and community development (HCD) and, more specifically, (2) "What is the relative influence of local housing AOs on support for HCD expenditures?" As discussed in the previous section of this article, the literature offers several theoretical explanations for decision-making and empirical studies identify numerous associations between contextual factors and policymaking. Thus, this research employs multiple regression analysis because this technique allows for the testing of competing, theoretically-derived hypotheses while controlling for other factors.

Prior to discussing the data and variables used in the analysis, it is important to recognize two assumptions of the study. First, the research assumes that affordable housing policies are redistributive (Basolo 1999a; Peterson 1981; Lowi 1972). Second, older organizations have a better understanding of the political environment of the city and are thus able to leverage this 
political knowledge to affect change (Amenta 2006; Andrews 2001; Meyer and Tarrow 1998).

This second assumption supports the use of specific proxies for the capacity of AOs to exert political influence as described in more detail below.

\section{Data}

The study examines larger U.S. cities, defined as those having a population of 100,000 persons or more. This population size assures the presence of adequate staff for affordable housing programming, as well as data availability (Basolo 1997), and has been effectively utilized in previous studies (e.g., Goetz 1995). The study uses secondary data from multiple sources including, the Census of Governments 2010, U.S. Census 2010, American Community Survey 2010, and the National Center for Charitable Statistics' (NCCS) Business Master File for 2008. The data were coded and combined at the city level.

The NCCS database presents a unique opportunity for this research. The NCCS is a clearinghouse of data on the nonprofit sector in the United States (Urban Institute 2014). The NCCS has a database of all active organizations along with information about each individual organization (e.g., type, state, name, revenue). All the organizations are, furthermore, classified according to the National Taxonomy of Exempt Entities (NTEE) (Urban Institute 2014). This taxonomy includes codes for the primary and secondary purposes of the nonprofit organizations. As Grønbjerg (1994) noted, the taxonomy focuses on the purpose rather than the economic activities the organization undertakes; this distinguishes the classification of this type of organization from their for-profit counterparts.

For this study, I used the NTEE taxonomy to include all nonprofit organizations classified under the major group "Human Services" within the activity area code "L - Housing and Shelter." This includes organizations involved in all types of activities within the housing 
and shelter activity area. The seven most common activity types (across all subsectors) are: alliance and advocacy organizations, management and technical assistance, professional societies and associations, research institutes and public policy analysis, single organization support, fund raising and fund distribution, and not elsewhere classified (N.E.C.). For example, organizations classified as alliances and advocacy organizations are groups whose activities focus on influencing public policy, including a variety of activities ranging from public education and influencing public opinion to lobbying national and state legislatures. Management and technical assistance organizations engage in consultation, training, and other forms of management assistance services to nonprofit groups. Research institutes and public policy analysis groups' primary purpose is to research outcomes of public policy initiatives and provide feedback to policymakers. Previous work has shown that nonprofit organizations whose core mission is to advocate for policy carry out the majority of advocacy services, but other nonprofit organizations, including those whose focus is on service provision, also play an important role in the advocacy process (See Kimberlin 2010; LeRoux and Krawczy 2014). For this research, therefore, I used all of the activity types identified within the housing and shelter major group area.

It is commonly believed that non-profit organizations exempt under the Internal Revenue Code 501(c) 3 are not allowed to lobby policymakers. However, the aforementioned section of the Internal Revenue Tax code specifically states that these groups may lobby and/or advocate as long as this does not constitute the majority of their activities. The magnitude of their activities is measured according to monetary parameters; thus, the amount of financial resources an organization dedicates to lobbying cannot exceed the resources dedicated to carrying out its 
primary mission. Political activity, understood as campaigning in favor of or against a political candidate, is strictly forbidden.

Data management procedures involved aggregating individual data sources to the desired geographic scale and organizing data for construction of key variables. The source and measurement of all variables, including the operationalization of key concepts, are discussed in the following section.

\section{Variables}

Multiple regression analysis is used to predict or explain a city's housing and community development expenditures as a function of several variables. The specification of the model in this study is guided by competing theoretical explanations and factors identified by empirical work in the extant literature. The dependent variable, operationalized as per capita annual expenditures on housing and community development ${ }^{6}$ (HCD), includes HCD expenditures for fiscal year 2009-2010 for all large U.S. cities as collected in the 2010 Census of Governments (for previous use of these data, see Schneider 1989) (see Table 1). The U.S Census Bureau defines HCD as "construction and operation of housing and redevelopment projects, and other activities to promote or aid housing and community development." ${ }^{77}$ These data are collected via a periodic, systematic survey of local governments in the U.S.

\section{Table 1 about here}

The primary relationship of interest in this study is between advocacy organizations and per capita HCD expenditures. Within the broader understanding of governance, AOs, also referred to as interest groups or nonprofit organizations (i.e., advocates for particular policies), 
may play an important role in city decision-making. In order to properly measure the influence of AOs within the policy process, the model's primary independent variables must capture the organizational capacities of AOs. Previous nonprofit organization research supports using size and age as proxies for the strength of an organization (see Crutchfield and Grant 2012; Light 2002). Moreover, support for these measures as predictors of AO political influence is well established in the urban policy literature (Vidal 1992; 1997; Gittell and Wilder 2002; Clay 1995). For this study, AO strength is captured through two measures. First, I developed an index that

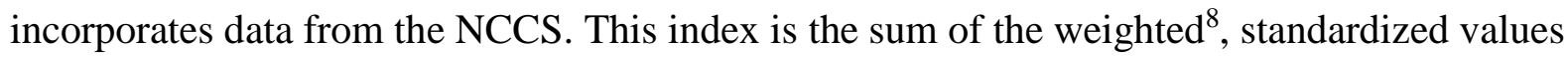
for three city-level variables: (1) the number of AOs classified as involved in "housing and shelter" activities; (2) the total revenue of these AOs in 2008; and (3) the total assets of these AOs in $2008^{9}$. The revenues and assets data are the values reported by each organization to the U.S. Internal Revenue Service for fiscal year $2008^{10}$. Second, age was measured as the mean age (in years) of the AOs in each city, using individual organizational ages from NCCS.

Additional variables about $\mathrm{AO}$ activity are included in the regression. Here I assume that that the influence of AOs is not limited to only the organizations in a city, but can also include AOs from surrounding areas. In other words, the analysis includes measures of AOs' strength, not only in the study city but also the strength of AOs within the county, to assess the influence of AOs in the rest of a city's region. I therefore, construct separate variables to account for this possibility. For each city, I create a measure of AO mean age and an index of strength (using the same indicators discussed above) for similar organizations in the entire county, excluding the organizations in the city of interest. Thus, in the analysis, there are two pairs of AO variables, one at the city level and one at the county level. 
The expectation that AOs impact city policymaking is supported in the literature. However, as discussed earlier, public choice theory offers an alternative explanation for city policymaking by focusing on inter-city competition. Therefore, I include a measure of inter-city competition in the analysis. This variable is measured, for each city, by adding all the cities and counties in the city's metropolitan statistical area (MSA) (see Basolo 1999a; Basolo and Lowery 2010).

The measures for contextual variables are based on previous studies. I drew upon Sharp's (2005) insights to measure new political culture. Thus, the political culture of a city was captured through the unconventional culture index developed by Sharp (2005). This index is composed by the sum of the Z-scores of the percentage of six city-level indicators from the U.S. Census and the U.S. Religious Census: (1) percentage of households not married with children present, (2) percentage of women in the labor force, (3) same-sex partner households per 1,000 households, (4) percentage of age $25+$ population with a B.A. or higher educational attainment, (5) inverse of church adherents as percentage of population, and (6) percentage of working population in scientific, technical, professional, or education occupation categories. To account for both the supply and demand side of housing affordability, I include a measure of the city's vacancy rate as the percentage of vacant houses (supply), and the sum of the percentage of owners and renters paying more than 30 percent of their income on housing (demand) (Quigley and Raphael 2004; Bogdon and Can 1997). Finally, city economic conditions is measured as an index of the sum of the standardized values of the city's median household income, minus the standardized unemployment and poverty rates (Basolo and Huang 2001). While fiscal conditions are measured by the ratio of city expenditures to revenue (for more on this measure see Maher and Deller 2007). 


\section{Analysis And Results}

The analysis uses ordinary least squares (OLS) regression. The cross-sectional regression model includes nine independent variables. The descriptive statistics for the dependent and independent variables are shown in Table 2. While the descriptive statistics for the composite or index variables are not particularly meaningful, the means for the per capita housing and community development expenditures, age of AOs, inter-city competition, and some contextual variables are of some interest. The mean per capita expenditures for large cities is 105.02 dollars. The average $\mathrm{AO}$ age for cities in the analysis is 16.33 years, while the average $\mathrm{AO}$ age for the larger county area is 13.98 years. These averages indicate that cities in the surrounding county, on average, have younger AOs than the larger cities. The mean value for inter-city competition reveals that larger cities have an average of 62.99 competitors in their region. The means for the variables that account for the housing conditions in larger U.S. cities highlight the housing affordability crisis large U.S. cities are experiencing. That is, almost 42 percent of the owner and renter households in large U.S. cities pay more than 30 percent of their income on housing. In all U.S. cities, the percentage of owner and renter households paying more than this proportion of their income on housing is a much lower 29 percent. Finally, among the cities in the study, the average vacancy rate for all housing is 9.45 percent, 5 percent lower than the national vacancy rate.

Table 2 about here

The regression analysis examines the influence of AOs, inter-city competition, and a set of contextual variables, on city support for affordable housing. Table 3 shows the results from the OLS regression analysis. 
Table 3 about here

The regression results confirm the initial expectation that the political maturity of the organizations doing advocacy work in a city (measured as mean age) has a statistically significant effect on per capita HCD expenditures. Specifically, on average, one extra year in AO mean age within the city results in a 4.2 percent increase in HCD spending per capita, all else being equal. Interestingly, the mean age of the organizations in the larger area around the city has a significant, negative effect on HCD expenditures per capita. This finding is consistent with Mancur Olson's (1965) finding of the "free rider" problem. In other words, a county with politically mature AOs outside the study city can result in less HCD expenditures in the study city because other neighboring cities may be influenced by these regional AOs and assume a portion of the study city's affordable housing burden. The AO strength index for city based AOs was statistically significant; on average, for every 10 percent increase in the city based AOs' financial strength index, there is about a 2.25 percent increase in per capita HCD expenditures. However, the strength index for the countywide (minus the city-based) AOs is not significant. Combined, these results may be due to the existence of AOs as long standing institutions in the community. This embeddedness may allow urban AOs to better navigate a city's political and institutional structure as well as placing them in more direct contact with their constituents. In comparison, AOs beyond a city's boundary are most influential due to longevity, which may translate into larger networks of relationships and political maturity. Thus, these AOs can exert influence on the city despite their location outside of the jurisdiction. 
The inter-city competition coefficient is not statistically significant which is contrary to expectations. Basolo (1999a; 1999b; 2000) found inter-city competition influenced city expenditures on affordable housing, but she considered only locally generated funds in her analysis. It may be that the dependent variable in this study, which captures per capita HCD expenditures using revenue from all levels of government (federal, state, and local), operates differently than anticipated, because pass through or entitlement dollars from higher levels of government may be targeted to certain activities and may not be seen as local expenditures by city officials. Furthermore, this finding may be influenced by the choice of city size of the studied population. Peterson (1981) argued that larger cities would do some redistribution; however, no clear city size threshold for this type of spending has been established in the literature.

Only two of the four contextual factors produced statistically significant results. Increasing the percentage of owners and renters that are housing cost-burdened by 1 percentage point in the city results in a 6.3 percent increase in $\mathrm{HCD}$ expenditures per capita. An increase in the percentage of units vacant by 10 percent brings about a 4.1 percent decrease in HCD expenditures per capita. These findings are consistent with housing needs and availability. Finally, the coefficients for political culture, fiscal conditions and for economic conditions have the expected signs, but are not statistically significant at the 0.05 level.

Overall, it is interesting to observe that the standardized coefficients indicate that the percentage of owner and renter households paying more than 30 percent of their income on housing, a contextual factor, has the strongest influence on HCD expenditures per capita, and city AO mean age is a close second followed by the city AO strength index. Therefore, while housing needs are clearly related to $\mathrm{HCD}$ expenditures, $\mathrm{AO}$ characteristics also are associated 
with higher levels of spending in this domain. In terms of explanatory power, the model performs reasonably well. The $\mathrm{R}^{2}$ for the model indicates that $27.7 \%$ of the variation in $\mathrm{HCD}$ expenditures per capita is explained by the independent variables in the model.

\section{Discussion}

AOs are agents that make claims and take action (in the public interest) to influence policymaking. Ultimately, these organizations seek to achieve lasting social change. In addition to establishing and organizing themselves, other factors must be present for AOs to wield influence. They must possess personal contacts and political knowledge and skill, as well as understand the current political environment and other intangible factors; all of which is achieved through age/experience of the organization. The finding, therefore, that the mean age of AOs both within cities and within the larger region influence HCD expenditures per capita is consistent with the literature. The finding that the strength (size, assets, and revenues) of AOs within the city impacted per capita HCD spending in the city also resonates with the literature.

The research provides evidence that AOs are important players in affordable housing policymaking within U.S. cities. However, the study does have some limitations that should be considered in interpreting the results. First, while the results support the theoretically-driven hypothesis that AOs impact spending on affordable housing in cities, the analysis is crosssectional and, therefore, cannot definitively establish direction of causality; it could be that HCD spending went to build AO capacity and thus influenced AOs strength. In other words, while theory is helpful in interpreting the direction of the relationship, the study is not designed to empirically prove that the relationship flows in one particular direction (it, in fact, could be bidirectional). Second, this study used HCD expenditures from all levels of government for the dependent variable. This measure may not be ideal to test for the effects of inter-city 
competition. Locally generated funds may be considered less restricted and generally more valuable than federal funds and, therefore, may reveal a competition effect.

Future research that would overcome the limitations of this work would require longitudinal data to provide more conclusive evidence that AOs are the cause of the changes in HCD policy expenditures. Intensive case studies of the interactions of AOs with cities would also provide further support to this claim and elaborate on the tactics used to influence policymakers $^{11}$.

\section{Conclusion}

This research examined the factors affecting city support for affordable housing. Specifically, it sought to better understand the influence of advocacy organizations (AOs) on city affordable housing spending decisions. Theories related to urban governance including hypotheses about interest group effects suggest that AOs, as stakeholders in the local decisionmaking process, will use their resources and experience to influence local policymakers and that their age and strength will predict their degree of influence on city decision-making. The analysis in this article provides support for these perspectives. This study suggests that older AOs in a city and in the larger region tend to exert more influence on local public policy, compared to younger, similar organizations. This finding is likely due to older AOs having longstanding and more mature networks of relationships in the community.

The study also showed that contextual factors are important to city spending decisions. Cities were more likely to exhibit increased spending on affordable housing in cities where housing was less affordable and they were less likely to spend more when there was an ample supply (or higher vacancy rate) of housing. Thus, this finding shows a direct connection between needs and spending. This connection also may reflect the source of HCD funds. If the 
funding for HCD expenditures came primarily from the federal government, then it may be calibrated to need by federal formula and have use restrictions that direct the money to areas of HCD need.

The current study uses quantitative analysis to provide a broad picture of the influence of AOs on local HCD expenditure decisions in larger U.S. cities. However, such an approach allows only a limited analysis of AO activity supporting affordable housing in cities. For example, it does not provide insights about the strategies and tactics employed in affecting the policymaking process. More intensive, qualitative research is necessary to understand the complexities involved in advocacy work; for example, we do not know how the strength of AOs influences choices about the strategies and tactics AOs employ to expand local support for affordable housing. Such an in depth study also would permit an investigation of local policies, other than direct spending, which encourage the creation of new affordable housing and the maintenance of existing housing stock (e.g., inclusionary zoning, rent controls, and density bonuses).

The work that provided the basis for this article was supported by a grant from the Haynes Foundation (John Randolph \& Dora) under Grant HF-100952, the Graduate Division at the University of California, Irvine (UCI), and the School of Social Ecology at UCI. The author also thanks and acknowledges Prof. Victoria Basolo and the anonymous reviewers for their comments on previous versions of this paper. The author is solely responsible for the accuracy of the statements and interpretations contained in the publication. Such interpretations do not necessarily reflect the views of the Haynes Foundation (John Randolph \& Dora) or the University of California, Irvine.

\section{Notes}

1 Housing affordability takes into account (at minimum) housing costs and income. It can be measured as an index, a wage-rent gap, or as a percentage of homes that can be purchased by households earning the median income of a specific area (National Association of Realtors, 2011; National Low Income Housing Coalition, 2011). A detailed discussion of affordability calculations is available in the 2004 Census Bureau's report on Housing Affordability (www.census.gov/housing/affordability). 
2 This work can lead to: a) the protection of existing government programs, 2) policy creation, 3 ) an increase in government funding, 4) citizen empowerment, and 5) improved policy implementation.

3 According to Section 501(c)(3) of the IRS Tax code, organizations registered under this taxexempt status are allowed to engage in lobbying as long as it is not a "substantial part" of their activities. 501(c)(4) social welfare organizations and 501(c)(6) trade associations may engage in lobbying activities without limits; in fact, these activities can sometimes be one of their main functions. As the "substantial part" definition is rather ambiguous, public charities that lobby should understand the monetary parameters for what constitutes "substantial." Political activity (i.e., campaigning in favor of or against a candidate), on the other hand, is strictly prohibited for these organizations. A violation of the IRS regulations may result in the organization losing its tax-exempt status or having to pay excise taxes on the money improperly spent.

4 Expenditures of city's own money, excluding funds from higher levels of government.

5 These strategies included supporting higher floor-area-ratios when developers agree to build LEED-certified silver structures and provide affordable housing units.

6 Housing and community development (HCD) expenditures, as defined by the Census of Governments, constitute "gross expenditures for urban renewal housing projects and similar activities" this expenditure category includes capital outlays (i.e., construction and purchase of equipment, land, and existing structures) as well as current operation expenses (i.e., employee compensation, supplies, materials, operating leases, and contractual services).

7 This variable is not a perfect measure of affordable housing expenditures because it includes other community development expenditures. However, it is a reasonable proxy based on a correlational analysis of HCD expenditures and 2010 budgeting data for affordable housing (collected in a 2013 survey) from 96 large U.S. cities. The correlation coefficient was .812 for this analysis (results available from the author).

8 This AO index was created using principal component analysis (PCA) to capture the relative variance each variable accounts for within the index. The eigenvalue for the first component, Advocacy Organization's assets, is 2.834 . The weights for each of the variables included in the index are as follows: assets (.345), income (.347), and number of AOs (.336).

92008 dollars were converted to 2011 dollars using an inflation conversion factor available at: http://oregonstate.edu/cla/polisci/sahr/sahr.

${ }^{10}$ All organizations filing as 501(c) are required to file a 990 form where they disclose their financial information.

${ }^{11}$ This study, with a longer timeline, is underway in four cities in the state of California.

\section{References}

Amenta, Edwin. 2006. When Movements Matter: The Townsend Plan And The Rise Of Social Security. Princeton, N.J: Princeton University Press.

Amenta, Edwin., Gardner, Beth. G., Tierney, Amber. C., Yerena, Anaid. and Elliott, Thomas. 2012. A Story-Centered Approach to the Newspaper Coverage of High-Profile SMOs. Research in Social Movements, Conflicts and Change 33: 83-107. 
Andrews, Kenneth T. 2001. Social movements and policy implementation: the Mississippi civil rights movement and the war on poverty, 1965 to 1971. American Sociological Review, 66(1), 71-95.

Andrews, K. T., and Edwards, Bob. 2004. Advocacy Organizations in the U.S. Political Process. Annual Review of Sociology, 30(1), 479-506.

Aurand, Andrew. 2007. The impact of regional government structure on the concentration and supply of affordable housing. Housing Policy Debate, 18(2), 393-430.

Basolo, Victoria. 1997. Housing policy in the local political economy: Understanding the support for affordable housing programs in cities. Dissertation. University of North Carolina, Chapel Hill, NC.

. 1999a. The impacts of intercity competition and intergovernmental factors on local affordable housing expenditures. Housing Policy Debate, 10, 659-688.

1999b. Passing the housing policy baton in the US: Will cities take the lead? Housing Studies 14(4): 433-452.

2000. City spending on economic development versus affordable housing: Does InterCity Competition or Local Politics Drive Decisions? Journal of Urban Affairs, 22(3), 317-332.

. 2003. US regionalism and rationality. Urban Studies, 40(3), 447-462.

Basolo, Victoria. and Huang, Chihyen. 2001. Cities and economic development: Does the city limits story still apply? Economic Development Quarterly, 15(4), 327-339.

Basolo, Victoria. and Lowery, David. 2010. Delineating the Regional Market in Studies of Intercity Competition. Urban Geography, 31(3), 369-384.

Berry, Jeffrey M. 1977. Lobbying for the people: The political behavior of public interest groups. Princeton, N.J.: Princeton University Press.

Bewley, Truman F. 1981. A critique of Tiebout's theory of local public expenditures. Econometrica: Journal of the Econometric Society, 713-740.

Blomquist, William 2007. The policy process and large-n comparative studies. In ed. Sabatier, Paul A. Theories of Policy Process. Boulder, Colo: Westview Press.

Bogdon, Amy S. and Can, Ayse 1997. Indicators of local housing affordability: Comparative and spatial approaches. Real Estate Economics, 25(1), 43-80.

Bohrnstedt, George. W. and Knoke, David. 1988. Statistics for Social Data Analysis. Itasca, IL: F.E. Peacock Publishers, Inc. 
Bostic, Raphael and Ellen, Ingrid G. 2014. Introduction: Special issue on housing policy in the United States. Journal of Housing Economics, 24, 1-3.

Bratt, Rachel G. 2012. The quadruple bottom line and nonprofit housing organizations in the United States. Housing Studies, 27(4), 438-456.

Bratt, Rachel G. and Keating, W. Dennis 1993. Federal Housing Policy and Hud Past Problems and Future Prospects of a Beleaguered Bureaucracy. Urban Affairs Review, 29(1), 3-27.

Browne, William P. 1998. Groups, Interests, and U.S. Public Policy. Washington, D.C: Georgetown University Press.

Campbell, John L. 1988. The collapse of an industry: Nuclear power and the contradictions of US policy. Ithaca, NY: Cornell University Press.

Campbell, Rebecca J. 2004. Leviathan and fiscal illusion in local government overlapping jurisdictions. Public Choice, 120, 301-329.

Clark, Cal and Walter, B. Oliver 1991. Urban Political Cultures, Financial Stress, and City Fiscal Austerity Strategies. The Western Political Quarterly.

Clark, Terry N. 1998. Overview of the book. In The new political culture. In Terry N. Clark and Vincent Hoffmann-Martinot (Eds.), 3-7. Boulder, CO: Westview.

Clark, Terry N., and Ferguson, Lorna C. 1983. City money: Political processes, fiscal strain, and retrenchment. New York: Columbia University Press.

Clay, Phillip N. 1995. Community organizations as housing developers. In R. F. America (Ed.), Philantropy and Economic Development. Westport, CT; Greenwood.

Cohen, David, Watson, Gabrielle, Oxfam America, and Advocacy Institute (Washington, D.C.). 2001. Advocacy for social justice: A global action and reflection guide. Bloomfield, CT: Kumarian Press.

Craig, Steven G. and Inman, Robert P. 1986. Education, welfare, and the new federalism: State budgeting in a federalist public economy. In Harvey S. Rosen (Ed.) Fiscal federalism: Quantitative studies, (33-78). Chicago: Chicago University Press.

Crutchfield, Leslie R. and Grant, Heather M. 2012. Forces for Good, Revised and Updated: The Six Practices of High-Impact Nonprofits. Vol. 403.

Davies, Jonathan S. \& Imbroscio, David (Eds), 2009. Theories of Urban Politics (2nd edition). London, UK: Sage Publications.

Dawson, Richard E. and Robinson, James A. 1963. Inter-party competition, economic variables, and welfare policies in the American states. The Journal of Politics 25, 265-89. 
Dowding, Keith, John, Peter and Biggs, Steven 1994. Tiebout: A survey of the empirical literature. Urban Studies, 31(4-5), 767-797.

Downs, Anthony 1994. New visions for metropolitan America. Brookings Institution Press.

Duncan, H. Daniels 2004. Advocacy and nonprofit organizations. In Dwight F. Burlingame (Ed.) Philanthropy in America: A comprehensive historical encyclopedia (pp. 9 -11). Santa Barbara, CA: ABC-CLIO.

Dye, Thomas R. 1965. Malapportionment and public policy in the states. The Journal of Politics, 27(3), 586-601.

Elazar, Daniel J. 1966. American federalism: A view from the States. New York: Crowell.

Epple, Dennis and Zelenitz, Allan 1981. The implications of competition among jurisdictions: does Tiebout need politics? The Journal of Political Economy, 1197-1217.

Fischel, William A. 2001. The homevoter hypothesis: How home values influence local government taxation, school finance, and land-use policies. Cambridge, Mass: Harvard University Press.

Fraser, Leah M. 2005. Participation and policy: A case study of environmental justice government-social movement interaction. University of California, Irvine, CA.

Gerardi, Kristopher, Ross, Stephen L. and Willen, Paul 2011. Understanding the foreclosure crisis. Journal of Policy Analysis and Management, 30 (2), 382-388.

Gittell, Ross and Wilder, Margared 2002. Community Development Corporations : Critical Factors That Influence Success. Journal of Urban Affairs, 21(3), 341-361.

Goetz, Edward G. 1995. Shelter burden: Local and progressive housing policy. Temple University Press, Philadelphia, PA.

Grønbjerg, Kristen 1994. Using NTEE to classify non-profit organisations: an assessment of human service and regional applications. Voluntas: International Journal of Voluntary and Nonprofit Organizations, 5(3) 301-328.

Horrigmo, Aase Marthe J. 2013. Can Culture Explain Culture? The Influence of Cultural Change on Municipal Spending on Cultural Policies. Urban Affairs Review. 49(3), 408-434.

Housing and Urban Development. 2009. Worst Case Housing Needs. Retrieved from: http://www.huduser.org/portal/periodicals/wchn.html. Accessed August 12, 2012.

Housing and Urban Development. 2013. U.S. Housing Market Conditions. Retrieved from: http://www.huduser.org/portal/periodicals/ushmc.html. Accessed September 8, 2013.

Innes, Judith E. and Booher, David E. 2004. Reframing public participation: strategies for the 21st century. Planning Theory \& Practice, 5(4), 419-436. 
Iversen, Roberta R., Napolitano, Laura and Furstenberg, Frank F. 2011. Middle-income families in the economic downturn: challenges and management strategies over time.

Longitudinal and Life Course Studies, 2(3), 286-300.

Jenkins, J. Craig 1995. The politics of social protest: Comparative perspectives on states and social movements. University of Minnesota Press.

Jimenez, Benedict 2009. Fiscal Stress and the Allocation Expenditure Responsibilities State and Local Governments: An Exploratory Study of between. State \& Local Government Review, 41(2), 81-94.

Kimberlin, Sara E. 2010. Advocacy by nonprofits: Roles and practices of core advocacy organizations and direct service agencies. Journal of Policy Practice, 9(3-4), 164-182.

Kriesi, Hanspeter 1995. The political opportunity structure of new social movements: Its impact on their mobilization. In J. Craig Jenkins (Ed.), The politics of social protest: Comparative perspectives on states and social movements. Pp. 167-98. Minneapolis: University of Minnesota Press.

LeRoux, Kelly and Krawczyk, Kelly 2014. Can Nonprofit Organizations Increase Voter Turnout? Findings From an Agency-Based Voter Mobilization Experiment. Nonprofit and Voluntary Sector Quarterly, 43(2), 272-292.

Levine, Charles H., Rubin, Irene S. and Wolohojian, George G. 1981. The politics of retrenchment: How local governments manage fiscal stress. Beverly Hills: Sage.

Lieske, Joel 2010. The Changing Regional Subcultures of the American States and the Utility of a New Cultural Measure. Political Research Quarterly, 538-552.

Light, Paul C. 2002. Pathways to nonprofit excellence. Brookings Institution Press.

Longoria, Thomas 1994. Empirical analysis of the city limits typology. Urban Affairs Review, 30(1), 102-113.

Lowi, Theodore J. 1972. Four systems of policy, politics, and choice. Public Administration Review, 32(4), 298-310.

Lucio, Joanna and Ramirez De la Cruz, Edgar 2012. Affordable housing networks: a case study in the Phoenix metropolitan region. Housing Policy Debate, 37-41.

Lyons, Wlliam E., Lowery, David and De Hoog, Ruth H. 1992. The politics of dissatisfaction: Citizens, services, and urban institutions. ME Sharpe.

MacIndoe, Heather and Whalen, Ryan 2013. Specialists, generalists, and policy advocacy by charitable nonprofit organizations. Journal of Sociology \& Social Welfare, 40, 119-149.

Maher, Craig and Deller, Steven 2007. Municipal Responses to Fiscal Stress. International Journal of Public Administration, 30, 1549-1572. 
Meyer, David S. 2012. Democracy and Democratization: Social Movements. In Amenta, Edwin, Nash, Kate, and Scott, Alan (Eds). The Wiley-Blackwell companion to political sociology. Pp. 395-407. Hoboken, NJ: John Wiley \& Sons.

Meyer, David S. and Tarrow, Sidney G. 1998. The social movement society: Contentious politics for a new century. Lanham: Rowman \& Littlefield Publishers.

Mueller, Dennis 2008. Public Choice: An Introduction. In Rowley Charles K. and Friedrich Schneider (Eds.) Readings in Public Choice and Constitutional Political, 1, 31-46.

Newman, Kathe and Ashton Philip 2013. Neoliberal urban policy and new paths of neighborhood change in the American Inner city. In Mueller, E., and Tighe, R. (Eds.). The affordable housing reader. Pp. 316-337. London: Routledge.

O'Connell, Lenahan 2012. Exploring the Contribution of State and Local-level Conditions to the Adoption of Different Types of Smart Growth Policies and Impact Fees in the United States. International Journal of Public Administration, 35(3), 194-203.

Olson, Mancur and Olson, Mancur 1965. The logic of collective action: public goods and the theory of groups (Vol. 124). Harvard University Press.

Parks, Roger B. and Oakerson, Ronald J. 1989. Metropolitan Organization and Governance A Local Public Economy Approach. Urban Affairs Review, 25(1), 18-29.

Percy, Stephen L., Hawkins, Brett W. and Maier, Peter E. 1995. Revisiting Tiebout: moving rationales and interjurisdictional relocation. Publius: The Journal of Federalism, 25(4), $1-17$.

Peterson, Paul E. 1981. City limits. Chicago, IL: University of Chicago Press.

Pierre, Jon 2014. Can Urban Regimes Travel in Time and Space? Urban Regime Theory, Urban Governance Theory, and Comparative Urban Politics. Urban Affairs Review, 1078087413518175.

Prakash, Aseem, \& Gugerty, Mary Kay 2010. Trust but verify? Voluntary regulation programs in the nonprofit sector. Regulation \& Governance, 4(1), 22-47.

Quigley, John M. and Raphael, Steven 2004. Is housing unaffordable? Why isn't it more affordable? The Journal of Economic Perspectives, 18(1), 191-214.

Rhodes, Roderick A. 2007. Understanding governance: Ten years on. Organization studies, 28(8), 1243-1264.

Rosdil, Donald 2011. Civic Culture, Sub-cultures, Non-traditionalism and Progressive Policy Using Value Change to Explain New US Development Strategies in the 21st Century. Urban Studies, 48(16), 3467-3486.

Rusk, David 1995. Cities Without Suburbs. Washington, D.C: Woodrow Wilson Center Press. 
Sandercock, Leonie 1998. The Death of Modernist Planning: Radical Praxis for a Postmodern Age. In Mike Douglass and John Friedmann (Eds.) Cities for Citizens: Planning and the Rise of Civil Society in a Global Age. New York: John Wiley \& Sons.

Schmitter, Philippe 2002. Participation in governance arrangements: Is there any reason to expect it will achieve 'sustainable and innovative policies in a multi-level context'? In: Jürgen R. Grote and Bernard Gbikpi (Eds.) Participatory Governance: Political and Societal Implications, Pp. 51 - 69. Opladen: Leske and Budrich.

Schneider, Mark 1989. The competitive city: The political economy of suburbia. Pittsburgh, Pa: University of Pittsburgh Press.

Schwartz, Alex F. 2010. Housing policy in the United States (Second Edition). Routledge New York.

Sharkansky, Ira 1969. The utility of Elazar's political culture: A research note. Polity, 66-83.

Sharp, Elaine B. 2005. Cities and Subcultures Exploring Validity and Predicting Connections. Urban Affairs Review, 41(2), 132-156. . 2007. Revitalizing Urban Research Can Cultural Explanation Bring Us Back from the Periphery?. Urban Affairs Review, 43(1), 55-75.

Slater, Rachel, \& Aiken, Mike 2014. Can't you Count? Public Service Delivery and Standardized Measurement Challenges-the Case of Community Composting. Public Management Review, (ahead-of-print), 1-18.

Stein, Robert M. 1987. Tiebout's sorting hypothesis. Urban Affairs Review, 23(1), 140-160.

Stoker, Gerry 1998. Governance as theory: five propositions. International Social Science Journal, 50(155), 17-28.

2000. Urban political science and the challenge of urban governance. In Pierre, J. (Ed.) Debating Governance Authority, Steering, and Democracy. (Pp. 91-109). Oxford: Oxford University Press.

Stone, Clarence N. 1976. Economic growth and neighborhood discontent. Chapel Hill: University of North Carolina Press.

Swyngedouw, Erik 2005. Governance innovation and the citizen: the Janus face of governancebeyond-the-state. Urban Studies, 42(11), 1991-2006.

Tiebout, Charles M. 1956. A pure theory of local expenditures. The Journal Of Political Economy, 64(5), 416-424.

Urban Institute. 2014. Nonprofit Organization and Program Classification. In: http://nccs.urban.org/classification/index.cfm. Accessed August 12, 2014. 
Vidal, Avis 1992. Rebuilding communities: A national study of urban community development corporations. New York: New School for Social Research, Communist Development Center. . 1997. Can community development reinvent itself? Journal of the American Planning Association, 63(4), 429-438.

Wassmer, Robert W. 2011. The recent pervasive external effects of residential home foreclosure. Housing Policy Debate, 21(2), 247-265.

Waste, Robert J. 1989. The Ecology of City Policy Making. New York: Oxford University Press.

Weiher, Gregory 1991. The fractured metropolis: Political fragmentation and metropolitan segregation. Albany, N.Y: State University of New York Press.

Wong, Kenneth K. 1990. City choices: Education and housing. Albany: State University of New York Press. 
